\title{
Language and linguistics
}

\section{LINGUISTIC THEORY}

81-221 Gray, Bennison. The impregnability of American linguistics: an historical sketch. Lingua (Amsterdam), 50, 1/2 (1980), 5-23.

Examination of the conflict between the mechanists (such as Bloomfield and Hall) and the mentalists (such as Spitzer and Chomsky) in American linguistics reveals that, despite irreconcilable differences, both schools are committed to a conception of science that prohibits debate on the fundamental issues. The party in power can and does change, but debate is always stifled by dismissing the outsiders as unscientific. For both, it is enough that linguistic inquiry be conducted scientifically for linguistic science to emerge. But what the nature and limits of such inquiry are, they neither agree upon nor debate. Consequently, the field is characterised by increasing paralysis, which spreads behind a façade rendered impregnable by the joint defence of irreconcilable opponents.

81-222 Lepore, Ernest. The problem of adequacy in linguistics. Theoretical Linguistics (Berlin), 6, 2/3 (1979), 161-72.

Chomsky's view concerning the task of the linguist has changed significantly. The Chomsky of Syntactic structures agreed with Quine about the need for behavioural tests for linguistic evidence, e.g. immediate comprehension, correct and uniform recall, normal intonation. But by 1964 he attacked Quine's adherence to operational definitions and embraced introspection. In a word, grammaticality was shifted from the domain of performance (situated use of language) to competence (tacit interior knowledge of rules). Against the later Chomsky, Stich has argued that the facts linguists uncover in their appeal to intuition do not support the existence of an underlying linguistic competence; rather, they reflect the speaker's capacity for perceptual judgments about proffered sound sequences.

This paper examines Stich's claims in the light of Quine's objection to the use of intuition; Quine's views on translation preclude such a method. It is concluded that there is no justification for limiting the evidence to 'stimulus meaning' alone, since, if the linguist knows the stimulus meaning of This sequence is grammatical for an informant, he knows how this informant distinguishes grammatical from ungrammatical sequences.

81-223 Mahmoudian, Mortéza. Structure linguistique: problèmes de la constance et des variations. [Linguistic structure: problems with variance and invariance.] Linguistique (Paris), 16, 1 (1980), 5-36. 
Linguistic phenomena can be located on a number of scales. One of these is the scale of distinctiveness: oppositions may be more or less distinctive (rather than being just either distinctive or non-distinctive). On the level of the individual speaker, there may be varying degrees of certainty or hesitation in the making of linguistic judgements, while on the level of society, there may be greater or lesser agreement between speakers. In terms of a linguistic description, these last two scales relate to the degree of regularity of the phenomena in question: those subject to the greatest uncertainty and lack of agreement will fit less neatly into a regular system. Alongside this 'extrinsic' scale, there is also an 'intrinsic' one based on the frequency of items and on their degree of integration in the linguistic system: the more frequent and/or integrated items will have a more central and less marginal place in the language. Finally, the 'extrinsic' and 'intrinsic' scales correlate directly with one another. [Application of these ideas to the collection of linguistic material, the analysis of signifies, and the establishment of syntactic categories].

\section{LINGUISTIC UNIVERSALS See also abstract 81-244}

81-224 Bondarenko, V. N. Средства выражения нехоторых универсалий предложения, обусловленных структурой выражаемой им мысли. [Means of expression of some universals of the sentence determined by the structure of the thought expressed.] Иностранные языки в шкопе (Moscow), 1 (1980), 26-31.

Panfilov's theory of levels of meaning of the proposition is discussed, according to which we must distinguish argument structure (concerning the relationships of objects in the real world) from subject-predicate structure (concerning the subjective presentation of these relationships by the speaker). These levels are said to be universal, giving rise to a typology of their expression in different languages.

The argument is illustrated with a typology of the means of marking predicates (in this specialised sense) in English, German and Russian. The major devices used for this purpose are sentence stress, articles, inroductory elements (such as there) in English, modal words, particles, cleft-type constructions and word order. Where the languages differ in terms of these devices, there is discussion of the problems of translation.

81-225 Pullum, Geoffrey K. Syntactic relations and linguistic universals. Transactions of the Philological Society (Oxford), 1980, $1-39$.

The topic of the paper is a number of grammatical notions employed by linguists, and especially the relations 'subject of ', 'direct object of' and 'indirect object of'. On Chomsky's view these three are derivative concepts, i.e. they are definable by reference to prior primitive notions in the theory of constituent structure. The paper rejects their derivative 


\section{LANGUAGE AND LINGUISTICS}

status; they are taken as theoretically primitive. Likewise rejected is the claim that an empirically based definition is available and that the concept 'subject' is a gradient one. Crucially, the notion of linguistic level should not be allowed to slip away. For this reason, two distinct levels are identified and labelled, viz. the initial level and the canonical level. Relations at the initial level are relevant for semantic purposes; they specify the basic structure of elements, and are fundamental to such operations as entailment prediction. The canonical level deals with relations that hold entirely within a given clause. In addition, a shallow level is posited, equivalent to the domain (in transformational grammar) of input to the first postcyclic rule.

The status of the claims of universal grammar is discussed. It is argued, for instance, that the notion 'basic order' of constituents or words is a genuine phenomenon, but only coherent within the framework of language-particular description. Hence, the discovery of languages with object-initial basic order means that no interesting theory of word order is possible, since all six basic types are now know to occur. The importance of linear order in transformational theory is seen to have led to the wrong choice of primitives, i.e. precedence and constituency. The price is arbitrariness and pseudo-formal vacuity.

\section{PRAGMATICS}

81-226 Van Valin, Robert D., Jr. Meaning and interpretation. Fournal of Pragmatics (Amsterdam), 4, 3 (1980), 213-31.

A discussion about the relationship between the meaning of linguistic elements, as traditionally investigated by linguists and philosophers, and the interpretation of speech in conversation and discourse. Starting from Wittgenstein's concept of the meaning of words being a function of their use and of language as part of forms of life, it is argued that the meaning of many linguistic elements is ultimately sociocultural in nature and that language can therefore be viewed as a system of sociocultural knowledge. The situated interpretation of speech in conversation is achieved through the process of conversational inference. Meaning and interpretation are found to be linked in two ways: first, sociocultural background knowledge is crucial in many cases for the use of words and for the interpretation of speech through conversational inference, and second, words often function as contextualisation cues which serve to create the context in which the utterance of which they are a part is to be interpreted. A holistic, pragmatically based framework is needed for linguistic theory and analysis. 


\section{LINGUISTIC DESCRIPTION AND ANALYSIS See also abstract 81-255}
81-227 Davison, Alice. Peculiar passives. Language (Baltimore, Md), 56, 1 (1980), 42-66.

Passive sentences often have different meanings and communicative intent from the corresponding active sentences. The 'extra' attitudinal and modal meanings of passive sentences are derived by Gricean conversational implicature. It is therefore possible to state the relation between active and passive sentences in syntactic terms without reference to meaning. Implicatures are more likely to be associated with passive sentences if the construction is 'marked', as measured by the restrictions placed on which NPs may be promoted to subject position, and what other roles the derived subject may have. Conversationally conveyed meanings are based on what appears as topic in subject position.

81-228 Eckman, Fred R. On the ordering of verbal prefixes and particles. Studies in Language (Amsterdam), 4, 1 (1980), 65-86.

In sentences such as (i) He looked up the information and (ii) $\mathrm{He}$ looked up the mountain, it has been standardly assumed that up in (i) is a verbal particle, and in (ii) is part of a prepositional phrase. The evidence for drawing such a distinction, viz. between particles and true prepositions, is extensive, and the accounts of the behaviour of verbal particles by Chomsky and Fraser, Ross, Sanders, and Emonds are reviewed. A new analysis of English verbal particles is proposed. It assumes that $(a)$ particles are gouped next to their associated verbs in deep structure, $(b)$ direct object pronouns must occur on the surface next to the associated verbs, and $(c)$ the permutation of particle and direct object (cf. (i) above with $\mathrm{He}$ looked the information $\mathrm{up}$ ) follows from a movement rule which reorders the direct object to a position next to the verb. The rule of Object Movement finds support from evidence from German, Hungarian, Serbo-Croatian, Russian, and a Chadic language. Such an analysis has consequences for a theory of linguistic change in terms of the status of syntactic rules as obligatory or optional.

81-229 Lundy, Robert. English elliptical sentences and co-ordinate conjunction. Studies in Language (Amsterdam), 4, 1 (1980), 87-103.

The standard TG account of certain forms of ellipsis in English is first summarised; in particular, the phenomena which grammarians have dubbed as 'gapped', 'secondary-conjoined' and 'conjunct-postposed' sentences, e.g. respectively, I ate fish, and Bill rice; I gave the boy a nickel and the girl a dime; Yohn will come-and Yoe too. Sentences like the last, however, have hardly been considered. The paper claims that there are no rules which are purely concerned with gapping or secondary conjunction; rather, that, like postposed conjuncts, they are an automatic 


\section{LANGUAGE AND LINGUISTICS}

result of the interplay of rules for simple co-ordination and for elliptical sentences. The ellipitcal sentence is interpreted in terms of what immediately precedes it, namely, the first conjunct. This analysis allows a simple and appealing view of elliptical sentences as conjuncts or syntactically separate.

\section{SOCIOLINGUISTICS See also abstract 81-285}

81-230 Beardsmore, H. Baetens. Bilingualism in Belgium. Yournal of Multilingual and Multicultural Development (Clevedon, Avon), 1, 2 (1980), 145-54.

Language is the most explosive force in Belgian political life. The origin of the major linguistic frontier between north and south probably arose out of demographic fluctuations in the Dark Ages. The bilingual capital, Brussels, originally Netherlandic-speaking, now forms a mainly Frenchspeaking enclave in the Netherlandic-speaking north. Around the capital and along the language frontiers are several areas which officially belong to one language community but which unofficially permit commerce and education in the other language for part of their population. Even within the officially monoglot areas there is a wide variety of dialects, and diglossia is common, with or without bilingualism.

Belgium probably has the heaviest linguistic legislation in the world. It is not clear how many of the population are bilinguals, but they are probably more numerous in the Netherlandic-speaking group, who are more willing to learn foreign languages than the French speakers. Education policy differs from region to region : there are three networks the state, the municipal, and the independent subsidised network operated mainly by the Catholic church. Language instruction plays an important role in the curriculum. Generally the second national language is taught, though the option is open to parental choice - English and German are often alternative choices.

The level of foreign-language knowledge in Belgium is considerably higher than in neighbouring states. Politicians tend to negate the positive aspects of bilingualism and promote regional monolingualism, although a large proportion of the population is in favour of increasing instruction in the second national language. Many speakers have a feeling of linguistic insecurity, and turn to outside models (France and Holland), which is resulting in a gradual decrease in the regional specificity of the languages spoken.

81-231 Blume, Regina. Graffiti in Schulen. Linguistische Aspekte informeller schriftlicher Schüleräußerungen. [Graffiti in schools: linguistic aspects of pupils' informal written utterances.] Zeitschrift für germanistische Linguistik (Berlin), 8, 2 (1980), 171-96. 
A linguistic analysis of the graffiti written by pupils in lesson-time. Most of the material was collected in a girls' school, though comparison is made with data from a boys' school. At the girls' school half the graffiti concern 'interpersonal relations'. As they get older, the girls become more concerned with friends than with figures from the world of entertainment. Rarely is mention made of politics, sport or sex. Among boys, there is more criticism of school, teachers and subjects, and a greater preoccupation with sport. In a questionnaire, three-quarters of the pupils attributed the writing of graffiti to boredom. It is suggested that graffiti provide an escape from the lesson. They are often meant solely for the eyes of the writer, who remains, and indeed wants to remain, anonymous. Syntactic analysis shows that most inscriptions are short, and fixed formulations frequent. [Extensive examples of graffiti.]

81-232 Gray, Bennison. Language as knowledge: the concept of style. Forum Linguisticum (Illinois), 3, 1 (1978), 29-45.

The alphabetic revolution in ancient $G$ reece led to the formation of a professionally literate caste in the West. The paper traces the rise and fall of this specialist class which acted as interpreters between the language of literary texts and the language of the people who were to become literate. The difference between these languages increased with time and literary conservatism; the concept of style justifies the use of one privileged variety of language. Aspiring members of the literate class tended to assimilate the values and conceptions of linguistic competence.

The literate caste has been thretened by the status of modern science as a source of knowledge par excellence; also by the spread and democratisation of literacy which has resulted in idioms requiring no special apparatus of interpretation and justification. There is a crisis in all intellectual activity that centres on the skills of literacy: the answers of the literati - symbolists, formalists, structuralists, TG grammarians, and many other movements - have in common the concept of style, i.e. the postulate of the verbal icon. If verbal signs are icons, then the student of language can learn about the world by exploring language. But language is not iconic, it is claimed; so the idea that language can be a source of knowledge is bound to be futile.

81-233 Gubb, Jenny. Language and role in mixed- and single-sex groups. Language for Learning (Exeter), 2, 1 (1980), 3-10.

This study aimed to look in some detail at the patterns of linguistic interaction in mixed- and single-sex groups. It sought to isolate language features that could be said to be sex-specific. A series of GCE ' $\mathrm{O}$ ' level and CSE oral discussion groups were tape-recorded. The four groups involved consisted of a single-sex group of four girls, a single-sex group of five boys, a mixed-sex group of three girls and one 


\section{LANGUAGE AND LINGUISTICS}

boy, and a mixed-sex group of five boys and one girl. The discussions were transcribed and the texts analysed according to differences which on a subjective reading seemed to be present. Variables analysed included: $(a)$ the number of interruptions; $(b)$ the number of overlaps (unsuccessful attempts to interrupt the speaker); $(c)$ the number of utterances indicating support; $(d)$ the number of challenges, and $(e)$ the number of utterances seeking to elicit the opinion of another speaker.

It was found that in mixed-sex groups boys spoke more often than girls even when the group was predominantly female. Boys interrupted more and were less willing to accept overlaps than girls. In both mixedand single-sex groups, girls were much more likely than boys to support the views of their colleagues. Only boys used challenges. Girls were more likely to try to draw others into the discussion. It follows that most girls and some boys will be 'linguistically deprived' in co-educational classes because their access to discussion is limited. Equal value needs to be given to the different discussion skills of boys and girls. 'Sexist' school materials should be analysed, not merely accepted.

81-234 Olsson, Lars. La politique culturelle de la France à l'égard de ses minorités linguistiques. [France's cultural policy towards linguistic minorities.] Moderna Språk (Saltsjö-Duvnäs, Sweden), 74, 3 (1980), 237-54.

The apparent linguistic uniformity of France conceals great diversity of regional languages. France is the West European country with the greatest number of linguistic minorities - Basque, Breton, Catalan, Corsican, Flemish, German and Occitan - yet these are treated with less generosity than almost anywhere else in the developed world. The policy of the French authorities has always been the assimilation and eventual disappearance of the local languages and the school has been its effective instrument ever since the introduction of compulsory education in the $1880 \mathrm{~s}$. The number of those speaking a regional language has declined dramatically, especially since the second world war. However, recent years have seen a cultural revival in the regions, which has led to renewed interest in their languages and to minimal concessions on the part of the authorities. Official policy constitutes a denial of human rights and is harmful to the linguistic development of minority-group children besides representing cultural impoverishment for the nation as a whole. Seven basic measures are suggested to preserve and maintain the regional languages in education, the media and administration.

81-235 Walters, Joel. Strategies for requesting in Spanish and English: structural similarities and pragmatic differences. Language Learning (Ann Arbor, Mich), 29, 2 (1979), 277-93.

This paper reports on recent work in the acquisition of pragmatic competence in a second language. It centres on the speech act of 
requesting and the semantic strategies for conveying that speech act. A contrastive analysis of Spanish and English strategies is undertaken to show that basically the same strategies are available in both languages. An experiment is described in which native speakers of each language were asked to judge the relative politeness of each strategy. An examination is made of the frequency of use of the various strategies for conveying requests among a population of bilingual children. The findings show that, while basically the same request strategies are available to speakers of Spanish and English, the use of the those strategies differs markedly. More polite strategies are employed in speaking Spanish, while more neutral strategies are used in English.

81-236 Wenzel, Angelika. Zum Verhältnis von verbaler und nonverbaler Kommunikation mit einer exemplarischen Analyse eines Gesprächsausschnitts. [The relationship between verbal and nonverbal communication, exemplified by an analysis of an extract from a conversation.] Deutsche Sprache (Berlin), 1 (1980), 1-20.

The article deals with the interrelationship between verbal and nonverbal communication. A brief survey of research work is given, concentrating on methods of quantitative content analysis and structuralism. A different method of analysing nonverbal behaviour in its verbal context is presented. An extract from a conversation between a department of employment official and an interviewee is analysed with the aim of demonstrating the relationship between the official's verbal and nonverbal behaviour.

The problem of identifying discrete units within the continuum of nonverbal behaviour is discussed, and aspects of behaviour are identified which can be used in defining these units. On the basis of the analysis it is suggested that bodily and facial gestures are used to add emphasis to linguistic utterances and that utterances felt by the speaker to be particularly important are often accompanied by a substantial number of pieces of nonverbal behaviour. The function of individual movements and gestures can only be identified within their linguistic and situational contexts.

\section{PSYCHOLINGUISTICS}

81-237 Fodor, J. A. and others. Against definitions. Cognition (Lausanne), 8, 3 (1980), 263-7.

Definitional accounts of language structure are explored. Several classes of arguments for definitions are reviewed; those which connect to: classical theories of reference, theories of informal validity, theories of sentence comprehension, and theories of concept learning. For each of these areas, accounts which rely upon definition are, in fact, not to 


\section{LANGUAGE AND LINGUISTICS}

be preferred on evidential grounds to plausible non-definitional alternatives. A series of experimental observations are presented, which relate to one of these areas - sentence comprehension. One widely cited class of examples of definitional structures, 'causative verbs', fails to affect subject judgments of those relations among the words of causative sentences which depend upon the putative definitional structures. Such subject judgments are independently demonstrated to be sensitive to structural relations of comparable type for other linguistically nonproblematic types.

81-238 Markman, Ellen M. and others. Classes and collections: principles of organisation in the learning of hierarchical relations. Cognition (Lausanne), 8, 3 (1980), 227-41.

This study demonstrates that children tend to distort class inclusion relations (e.g. the relation of oaks to trees) into the part-whole structure of collections (e.g. the relation of oaks to a forest). Children aged 6 to 17 were taught novel class inclusion hierarchies, analogous to the relation between oaks, pines and trees. In one condition, the class inclusion relations were taught by ostensive definition alone, e.g. stating 'These are trees' while pointing to trees, and 'These are oaks', while pointing to oaks. In the second condition, children were additionally told what would be analogous to 'Oaks and pines are two kinds of trees'. With this additional information to constrain their interpretation, even the youngest children correctly interpreted the relation as class inclusion. In contrast, with limited information, children as old as 14 erroneously imposed a collection structure on the inclusion hierarchies. They would deny, for example, that any single tree was a tree (as they should if they thought 'tree' meant 'forest'), and would pick up several trees despite being asked for a tree. The results indicated that the part-whole structure of collections is simpler to establish and maintain than the structure of inclusion.

81-239 Wolf, Dieter. Wortbildung in einer realen Sprecher-HörerGrammatik. [Word formation in a real speaker-hearer grammar.] Die neueren Sprachen (Frankfurt am Main), 29, 3 (1980), 244-58.

Every speaker-hearer in a language community possesses a different degree of competence with respect to the formation and the understanding of morphological derivations. These variations in competence can be explained in terms of differences between individual speakers' relative exposures to derivational linguistic data, psychological processing mechanisms, and social origins. 


\section{LANGUAGE DEVELOPMENT OF CHILDREN}

81-240 Erreich, Anne and others. Aspects of a theory of language acquistion. Yournal of Child Language (Cambridge), 7, 1 (1980), 157-79.

This paper presents a hypothesis-testing tineory of syntax acquisition. The first section presents the model. It is clamied that: (1) children learn a transformational grammar, including a set of phrase structure and transformational rules; (2) linguistic universals and Occam's razor constrain the initial hypothesis space available to the device; (3) hypotheses tested by the device consist of candidate phrase structure and transformational rules; (4) linguistic evidence confirms or disconfirms hypotheses. Specific examples of incorrect phrase structure and transformational hypotheses are presented.

The second section briefly surveys other approaches to language acquisition - both syntactic and non-syntactic - and compares them to this model. In the third section, several methodological issues are addressed: (1) the relevance of linguistic theory to the model; (2) how the model is tested; (3) the domain of the theory.

81-241 Gray, Vicky A. and Cameron, Catherine Ann. Longitudinal development of English morphology in French immersion children. Applied Psycholinguistics (Cambridge), 1, 2 (1980), 171-81.

Development of plural and past tense morphological rules was examined longitudinally with 272 English-speaking children enrolled in French immersion or traditional English curricula. Children were tested in grades one through four on 18 items from Berko's test (1958). There were no performance differences betwen the two curriculum groups, girls performed better than boys, and there were correlations between intelligence and performance. Syllables requiring the plural $/-z /$ and past tense / $-d /$ and / $t$ / were acquired earlier than those calling for / $-\partial z /$ or /-əd/. Inflection acquisition was orderly and sequential within subjects. By age 10 children began using adult-like irregular formations, but regular or overregularised forms preceded irregulars. Whereas by 10 years, basic rules were mastered, more difficult forms were still developing.

81-242 Wolf, J. Gerard. Language acquisition and the discovery of phrase structure. Language and Speech (Hampton Hill, Middx), 23, 3 (1980), 255-69.

A computer programme intended as a step towards an empirically adequate theory of first-language acquisition by children is presented. It has been tested on a sample of English transcribed as a sequence of word classes. The structures formed by the programme correspond in many cases with recognised structures in English, and there is a 


\section{LANGUAGE AND LINGUISTICS}

significant correspondence between a parsing of the sample by the programme and conventional surface-structure analysis. Anomalies in the programme's performance are discussed.

\section{BILINGUALISM See abstract 81-230}

\section{PHONETICS AND PHONOLOGY See also abstract 81-273}

81-243 Fischer, Robert A. La phonologisation du schwa en français. [The phonologisation of schwa in French]. Lingvisticae Investigationes (Amsterdam), 4, 1 (1980), 21-38.

French schwa is analysed as the phonological vowel segment $/ \dot{\alpha} /$. This differs from $/ \propto /$ only by the diacritic feature specification [-stable], which accounts for the fact that $/ \dot{\alpha} /$ may delete (la semaine [lasœmen] [lasmen]) whereas / $\propto /$ may not. The various phonetic realisations of $/ \dot{\propto} /$ are accounted for by a series of rules. The proposed historical reanalysis of schwa from the central vowel /ə/ to the front vowel $/ \dot{\propto} /$ is discussed in detail, and is explained in part by the supposed reanalysis of $/ 0 /$ as central $/ / 3 /$.

81-244 Katamba, Fracis. How hierarchical and universal is consonant strength? Theoretical Linguistics (Berlin), 6, 1 (1979), $23-40$.

The claim that the notion of universal consonant strength hierarchies should be incorporated in phonological theory because $(a)$ it offers phonologists a valuable heuristic device for predicting the direction of strengthening and weakening processes, and $(b)$ it can reveal significant phonological relations, is considered and rejected after scrutinising evidence which indicates that such hierarchies are not universal and that their predictive power may be uncertain even within a single language. Consequently it is argued that these objections invalidate an approach like that proposed by Foley (1977) in which universal consonant strength hierarchies play a pivotal role.

81-245 MacNeilage, Peter F. Speech production. Language and Speech (Hampton Hill, Middx), 23, 1 (1980), 3-23.

A status report is given on three areas of speech production. (1) Functional properties of the speech production apparatus: the current state of knowledge of the respiratory, phonatory and articulatory systems is briefly discussed. (2) Control principles underlying speech production: the nature of the supposed invariance underlying segment production, theories of coarticulation, the relation between control units and linguistic units, peripheral neurophysiology and mechanics, and Action Theory. (3) The biological basis of the speech production 
process: discussion of whether discontinuity in vocal tract evolution is accompanied by discontinuity in linguistic evolution, presentation of evidence that babbling is an important precursor to early speech, and a discussion of interhemispheric and intrahemispheric localisation of linguistic functions.

81-246 Wheeler, Cathy J. and Schumsky, Donald A. The morpheme boundaries of some English derivational suffixes. Glossa (Burnaby, BC), 14, 1 (1980), 3-34.

It is not always obvious where the morphene boundaries of suffixes are located, as, for example, in English words like decision and explosive. Three experiments were carried out to discover where speakers place the morpheme boundaries of a number of English derivational suffixes. Subjects were not uniform in their suffix choice for words with uncertain boundaries, and they did not always segment theoretically segmentable words, both of which are evidence against the simplicity metric of generative phonology. Subjects' responses can be analysed as being the result of applying one of three strategies for determining a suffix, and there is a hierarchy of strategy preference. Strategy choice is affected by both phonological and orthographic change in the stem resulting from the addition of a suffix.

\section{LEXICOGRAPHY}

81-247 Marín, Diego. Los 'falsos amigos' en español/inglés. ['False friends' in Spanish/English.] Canadian Modern Language Review (Toronto), 37, 1 (1980), 65-98.

A list of about 1000 so-called 'false friends' or pseudo-cognates in Spanish/English was compiled by a research team from the University of Toronto, with the double aim of completing previous lists, and of offering a useful tool for translators and students of both languages by adopting a double-entry format in parallel columns, Spanish-English and Inglés-Español. The author identifies as false cognates those which have a common etymological and morphological origin but whose semantic development has resulted in different meanings (librerialibrary), or which have the same meaning in a certain sense but not in another $(c o p a-c u p)$, in which case the true cognate meaning is indicated by square brackets. Excluded are heteronymous terms with identical spellings in both languages but belonging to unrelated semantic fields, since their entirely different meanings should be evident from first contact with the words (e.g. dame in English and Spanish). Since the list reflects standard contemporary language, colloquial or figurative meanings are given only when commonly used in their linguistic area, either Latin or North America. Archaic usage is specified only in a few significant cases. 
CONVERSATIONAL ANALYSIS See also abstract 81-236

81-248 Arndt, Horst and Janney, Richard W. The clanger phenomenon: the non-deviant nature of deviant utterances. IRAL (Heidelberg), 18, 1 (1980), 41-57.

A discussion of instances of conversational disruption caused by a type of utterance called the 'clanger', i.e. an interactionally aggressive utterance which disrupts the expected sequencing of verbal moves in a conversation, for purposes of redefining the relationships between the participants in the interpersonal domains of hostility-affection and dominance-submission. They figure in identity bargaining sequences. Many of the disruptive linguistic features of clanger phenomena can be described in terms of simple contrastive linguistic scales. At the phonological level these scales measure shifts among features such as loudness, stress, pitch, inflection, variance and speech rate; at the lexical level they measure shifts in formality, forms of address and connotative meanings; and at the syntactic level they measure shifts in utterance complexity and length. Using contrastive scales it is possible to describe the formal linguistic differences which set clangers apart from other utterances in utterance sequences.

Interpersonal factors also need to be taken into account; they can be represented on bi-polar scales (hostility-affection, etc.), to complement the linguistic analysis. Clangers are not deviant but divergent utterances.

81-249 Maynard, Douglas W. Placement of topic changes in conversation. Semiotica (The Hague), 30, 3/4 (1980), 263-90.

Topicality in talk is a matter not only of content but of structure. Conversationalists 'fit' their current utterance to that of the prior speaker by means of a variety of procedures which this paper elaborates. Topic change is considered as a solution to a problem of unsuccessful transfer of speakership. When talk falters in certain characteristic ways, topic change is regularly used to restore a state of continuous talk. The data base was 22 two-party conversations lasting 12 minutes between university students in an experimental setting.

Topic talk can expire in various ways, often producing silence. To start the turn-by-turn talk again, speakers in the study frequently resorted to the topic of the experiment itself. Where the topic changed to matters outside the setting, there were obvious differences according as the speakers knew each other or not. If they did, the topic-changing utterance took the form of an announcement: if not, the utterance was an invitation in question form. 


\section{NEEDS ANALYSIS}

81-250 Dos Ghali, Dominque and Tremblay, Dennis. Recherche des besoins langagiers d'adultes en milieu professionnel. [Research on the language needs of adults in professional jobs.] Canadian Modern Language Review (Toronto), 36, 3 (1980), 434-43.

This project was conducted by the Department of External Affairs in an effort to provide specialised second-language instruction in French to Candian diplomats required to work in their second language in a number of specialised areas relating to the foreign service, work necessitating in many instances a high degree of fluency and precision in the written and oral use of the second language. In order for advanced level training to be effective, it was neccessary to define the precise needs of the clientele in terms of the communicative skill in the second language, to determine the specific vocabulary and structural patterns which are involved in the subject areas in which they work, and to develop the teaching and learning strategies appropriate for effective second-language learning at a fairly advanced level. A definition of the communicative skill to be acquired was accomplished by an exhaustive study of the nature and frequency of 'communicative situation' encountered by officers in the Department and abroad. A comprehensive questionnaire based on the needs identification model developed by Richterich, was administered in individual interviews to 200 officers. 